\title{
Measurement of lung volume and optimal oxygenation during high frequency oscillation
}

\author{
Gabriel Dimitriou, Anne Greenough
}

\begin{abstract}
Twelve infants, median gestational age 27 weeks and postnatal age 1 day, were examined to determine whether oxygenation improves on transfer to high frequency oscillation (HFO). Lung volume was assessed before transfer to HFO by measuring functional residual capacity (FRC) using a helium gas dilution technique and specially designed infant circuit. On transfer to HFO, the inspired oxygen was initially kept constant, but the mean airway pressure (MAP) increased until maximum oxygenation was achieved (optimal MAP). The median FRC of the 12 infants before HFO was $8.1 \mathrm{ml} / \mathrm{kg}$ (range 4.7 to 28.7 ) and their median alveolararterial oxygen gradient (A-aDO $\left.{ }_{2}\right)$ $484 \mathrm{~mm}$ Hg. On transfer to HFO, oxygenation did not improve in two infants, but, overall, the $\mathrm{A}-\mathrm{aDO}_{2}$ fell to a median of 289 mm Hg $(p<0.05)$. The median optimal MAP was $18.5 \mathrm{~cm} \mathrm{H}_{2} \mathrm{O}$ (range 10.6 to $24 \cdot 4$ ) and this had an inverse correlation with the FRC before starting HFO $(p<0 \cdot 01)$. The median change in MAP needed to maximise oxygenation on HFO also correlated negatively with FRC $(\mathbf{p}<\mathbf{0 \cdot 0 1})$.

(Arch Dis Child 1995; 72: F180-F183)
\end{abstract}

Keywords: lung volume, high frequency oscillation, functional residual capacity.

Transfer to high frequency oscillation (HFO) can improve oxygenation in infants whose respiratory failure has responded poorly to conventional ventilation. ${ }^{1}$ When a 'high volume' strategy is pursued the improvements in oxygenation seen when the mean airway pressure (MAP) is increased may be attributable to the opening up of atelectatic lungs and the maintenance of the lung above its closing volume. ${ }^{2}$ If that supposition is correct then infants with the lowest lung volume would require the greatest increase in MAP to optimise oxygenation. To test that hypothesis we assessed lung volume by measuring functional residual capacity (FRC) before transfer to $\mathrm{HFO}$ and related this to the absolute and change in MAP level necessary to maximise oxygenation.

Department of Child Health, King's College Hospital, London SE5 9RS

G Dimitriou

A Greenough

Correspondence to: Professor A Greenough.

Accepted 22 January 1995

\section{Methods}

Infants were transferred to $\mathrm{HFO}$ if their respiratory failure was deemed by the clinician in charge to be responding poorly to conventional ventilation. This was defined as a requirement for an inspired oxygen concentration $\left(\mathrm{FIO}_{2}\right)$ of 0.5 or greater and/or a MAP of at least $10 \mathrm{~cm}$ $\mathrm{H}_{2} \mathrm{O}$ to maintain the $\mathrm{pH}$ between $7 \cdot 25$ and $7 \cdot 40$, arterial oxygen tension $\left(\mathrm{PaO}_{2}\right)$ between 6.67 and $12.0 \mathrm{kPa}$ (50 and $90 \mathrm{~mm} \mathrm{Hg}$ ), and arterial carbon dioxide tension $\left(\mathrm{PaCO}_{2}\right)$ between 4.67 and $6.67 \mathrm{kPa}$ (35 and $50 \mathrm{~mm} \mathrm{Hg}$ ). Their respiratory status was confirmed by measuring a blood sample taken from an indwelling arterial line sited for clinical purposes.

Immediately before transfer to HFO, FRC was estimated twice in each infant, with an interval of 10 minutes between measurements. Infants were measured in a supine position. A helium gas dilution technique and specially designed infant circuit with a circuit volume of $95 \mathrm{ml}$ was used. ${ }^{3}$ The measurement technique has been described in detail before. ${ }^{4}$ The FRC system contains a rebreathing bag - the system reservoir - enclosed in an airtight cylinder. During measurement, the infant's endotracheal tube is connected to the rebreathing bag via a three-way valve. The ventilator is also connected to the three-way valve and the valve is connected to a side port on the airway cylinder. The infant can therefore be ventilated directly or, once the position of the three-way valve is changed, to breathe from the rebreathing bag whilst receiving positive pressure support by changes in pressure within the cylinder, resulting in compression of the rebreathing bag. The helium analyser (Equilibrated Biosystems) has a digital display which was recorded before and at 15 second intervals during the measurement. Equilibration was assumed when there was similar helium concentration over a 30 second interval. The initial and equilibration helium concentrations were used in the calculation of FRC. FRC results were corrected for oxygen consumption, assumed to be $7 \mathrm{ml} / \mathrm{kg} /$ minute, ${ }^{5}$ and the results were then corrrected for body temperature under pressure saturated conditions. The FRC was expressed as the mean of the paired measurements.

HFO was provided by a SensorMedics $3100 \mathrm{~A}$ oscillator. When changing to HFO, the same $\mathrm{FIO}_{2}$ used during conventional ventilation was initially maintained, a frequency of $10 \mathrm{~Hz}$ and fractional inspiratory time of 0.30 were used. The oscillatory amplitude was adjusted until visible chest wall vibration was observed. The initial MAP on HFO was that used during conventional ventilation immediately before transfer. The MAP was then increased in $2 \mathrm{~cm} \mathrm{H}_{2} \mathrm{O}$ increments after 10 minute intervals until $6 \mathrm{~cm} \mathrm{H}_{2} \mathrm{O}$ above that used during conventional ventilation was 


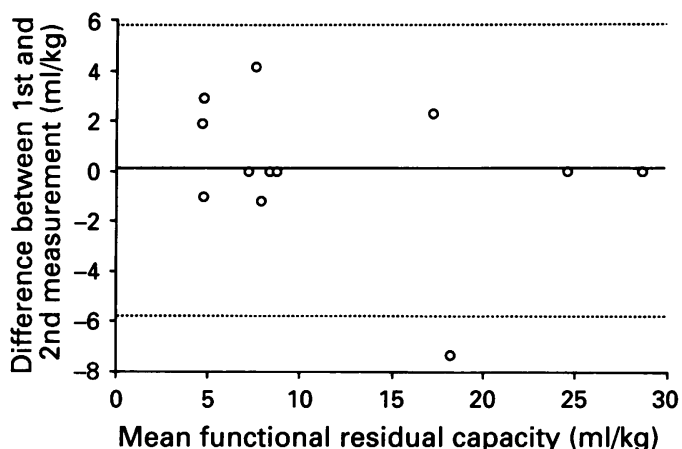

Figure 1 The difference between the first and second FRC measurements related to the individual's mean FRC. The mean difference is demonstrated by the solid horizontal line; the dotted lines indicate $\pm 2 S D$ s from the mean.

reached. If no change in $\mathrm{PaO}_{2}$ had occurred then the settings remained unchanged for 30 minutes. If after that time there was still no improvement in $\mathrm{PaO}_{2}$ (confirmed by an arterial blood gas sample), the MAP was reduced by 2 $\mathrm{cm} \mathrm{H}_{2} \mathrm{O}$ increments until the MAP on conventional ventilation was reached. If during that period and after a further 30 minutes there was no increase in oxygenation, again confirmed by arterial blood gas sampling, the infant was subsequently returned to conventional ventilation. The optimal MAP under these circumstances was deemed that of conventional ventilation (the change in MAP being zero). If the $\mathrm{PaO}_{2}$ had improved as the MAP was being increased an increase in MAP continued until no further improvement was experienced, and that level was then maintained for 30 minutes. If there was no further change in oxygenation, confirmed by arterial blood gas sampling, that MAP level was designated optimal. If, however, oxygenation further improved, MAP was again increased until the maximum $\mathrm{PaO}_{2}$ had been reached. If at any stage there was a deterioration in oxygenation the infant was returned to the MAP level immediately below.

Throughout the study, the infants were continuously monitored using both transcutaneous oxygen monitoring and oxygen saturation. Some infants also had intra-arterial $\mathrm{PaO}_{2}$ electrodes, and all had indwelling arterial catheters. If, at any time, the continuous monitoring showed that the infant's $\mathrm{PaO}_{2}$ was greater than $12.0 \mathrm{kPa}(90 \mathrm{~mm} \mathrm{Hg})$, then the inspired oxygen concentration was appropriately reduced. The optimal MAP was defined as that at which maximum oxygenation was experienced, demonstrated by continuous monitoring and confirmed by arterial blood sampling. Alveolar-arterial oxygen gradients $\left(\mathrm{A}-\mathrm{aDO}_{2}\right)$ were calculated from the arterial blood gases taken immediately before transfer to HFO and at the optimal MAP level. The $\mathrm{A}-\mathrm{aDO}_{2}$ was calculated according to the following formula:

[Barometric-water vapour pressure $\left.\times \mathrm{FiO}_{2}-\mathrm{PaCO}_{2}-\mathrm{PaO}_{2}\right](\mathrm{mm} \mathrm{Hg})$

Barometric pressure $=760 \mathrm{~mm} \mathrm{Hg}$; water vapour pressure $=47 \mathrm{~mm} \mathrm{Hg}$.

Once the optimal MAP had been established, as is our usual clinical practice, a chest radiograph was performed to assess whether there was evidence of hyperinflation. This was diagnosed by thinning of the cardiac silhouette, flattening of the diaphragms, and exposure of more than eight posterior ribs.

The coefficient of repeatability of the FRC measurement was calculated according to the method of Bland and Altman (fig 1). ${ }^{6}$ The difference between paired measurements was calculated for each individual. The sum of these differences squared was divided by the number of subjects, the square root of the result being the standard deviation of the differences. Twice this standard deviation gave the coefficient of repeatability.

The optimal MAP level was that at which maximum oxygenation was achieved. The change in MAP necessary to maximise oxygenation was calculated by subtracting the MAP level on conventional ventilation from the optimal MAP level. Differences between groups were assessed for significance using the Wilcoxon signed rank test. Correlations between FRC and the optimum MAP or change in MAP were assessed for significance by calculation of Spearman's rank correlation coefficients.

Twelve infants were included in the study; their diagnoses were respiratory distress syndrome (RDS) $(n=6)$, meconium aspiration syndrome (MAS) $(n=4)$, congenital pneumonia $(n=1)$ and pulmonary haemorrhage $(n=1)$. Their median gestational age was $26 \cdot 5$ weeks (range 23-42), birthweight $0.907 \mathrm{~kg}$ $(0.536-4 \cdot 296)$, and postnatal age 1 day (1-3). The infants were initially ventilated using Sechrist IV ventilators (Sechrist Industries Inc), and oral shouldered endotracheal tubes.

Immediately before transfer to HFO the infants were receiving a median peak inspiratory pressure of $24.5 \mathrm{~cm} \mathrm{H}_{2} \mathrm{O}$ (range 17-41), a MAP of $11.1 \mathrm{~cm} \mathrm{H}_{2} \mathrm{O}(7 \cdot 90-17 \cdot 60)$, and an $\mathrm{FIO}_{2}$ of $0.8(0.48-1 \cdot 0)$. At the time of transfer the infants' median $\mathrm{A}-\mathrm{aDO}_{2}$ was $484 \mathrm{~mm} \mathrm{Hg}$ (range 240-626). Nine infants had received surfactant (six who had RDS and three infants with MAS). Except for one infant with MAS who received a natural surfactant (Survanta), an artificial surfactant (Exosurf) was used. All the measurements of FRC were made at least one hour after surfactant had been given, a median time of two hours (range one to 12). The infant given Survanta was studied after one hour.

\section{Results}

The median FRC before transfer was $8 \cdot 1 \mathrm{ml} / \mathrm{kg}$ (range 4.7 to $28 \cdot 7$ ). The equilibration time was in a median of 30 seconds (range 30-60). The mean difference in FRC between an individual's paired measurements was $0.14 \mathrm{ml} / \mathrm{kg}$ (range -7.30 to $4.13 \mathrm{ml} / \mathrm{kg}$ ), standard deviation (SD) of the differences being $2 \cdot 86$ (fig 1 ). The coefficient of repeatability of FRC measurements was $5.72 \mathrm{ml} / \mathrm{kg}$. Infants with RDS tended to have the lowest FRCs (table). During HFO, maximum oxygenation was achieved at a median MAP level of $18.5 \mathrm{~cm}$ $\mathrm{H}_{2} \mathrm{O}$ (range 10.6 to 24.4 ); this necessitated a change in MAP of a median of $7 \mathrm{~cm} \mathrm{H}_{2} \mathrm{O}$ 
Correlation between FRC, optimal MAP, and change in MAP to diagnosis median (range)

\begin{tabular}{lllll}
\hline & $n=$ & $\begin{array}{l}F R C \\
(\mathrm{~mL} / \mathrm{kg})\end{array}$ & $\begin{array}{l}\text { Optimal MAP } \\
\left(\mathrm{cm} \mathrm{H}_{2} \mathrm{O}\right)\end{array}$ & $\begin{array}{l}\text { Change in MAP } \\
\left(\mathrm{cm} \mathrm{H} \mathrm{H}_{2} \mathrm{O}\right)\end{array}$ \\
\hline RDS & 6 & $7 \cdot 8(4 \cdot 7-8 \cdot 5)$ & $19 \cdot 5(15 \cdot 1-23 \cdot 5)$ & $7 \cdot 7(4 \cdot 8-10)$ \\
MAS & 4 & $12 \cdot 3(4 \cdot 7-28 \cdot 7)$ & $16 \cdot 8(10 \cdot 6-24 \cdot 4)$ & $3 \cdot 4(0-11 \cdot 2)$ \\
Pulmonary haemorrhage & 1 & $18 \cdot 3$ & $18 \cdot 5$ & $7 \cdot 9$ \\
Congenital pneumonia & 1 & $24 \cdot 5$ & $13 \cdot 8$ & $2 \cdot 9$
\end{tabular}

(range 0 to $11 \cdot 2$ ). In all but one infant, the $\mathrm{PaCO}_{2}$ decreased on transfer to HFO, median decrease $2.0 \mathrm{kPa}$, range -1.2 to $4(15 \mathrm{~mm} \mathrm{Hg}$, range -9 to 30 ). Two infants did not experience an improvement in oxygenation on transfer to HFO - both infants had MAS but only one had received surfactant (Exosurf). No infant at the optimal MAP level was hyperinflated, as assessed by chest radiograph appearance. At the optimum MAP level the infants had a median $\mathrm{A}-\mathrm{aDO}_{2}$ of $289 \mathrm{~mm} \mathrm{Hg}$ (range 114 to 630 ); this was lower than that experienced on conventional ventilation $(\mathrm{p}<0.05)$. The median decrease in the $\mathrm{A}$ $\mathrm{aDO}_{2}$ was $97 \mathrm{~mm} \mathrm{Hg}$ (range -32 to 394 ). Both the optimal MAP level (optimal $\mathrm{MAP}=-0.42 \mathrm{FRC} \mathrm{ml} / \mathrm{kg})+22.88, \mathrm{r}=-0.80$ ) and the change in MAP level (fig 2) necessary to maximise oxygenation had a significant inverse correlation with FRC $(p<0.01)$. There was no significant correlation between the change in $\mathrm{A}-\mathrm{aDO}_{2}$ and FRC.

\section{Discussion}

Ten of the 12 infants examined experienced an improvement in oxygenation on transfer to HFO when a high volume strategy was pursued. An initial ceiling to the change in MAP level was set at $6 \mathrm{~cm} \mathrm{H}_{2} \mathrm{O}$. We chose that level, because in a previous study ${ }^{7}$ oxygenation had improved in all infants when such a change in MAP had been used. The patients included in the earlier report ${ }^{7}$ were all born prematurely and had RDS, and were thus expected to have non-compliant, low volume lungs. We examined infants with a variety of diagnoses and gestational ages and hence predictably non-uniform lung function (table). We were therefore not surprised to find a variable response to HFO. If an infant has atelectatic lungs, the lung must be inflated above the pressure at which it opens and then be maintained above its closing pressure for oxygenation to improve. ${ }^{2}$ Although increasing

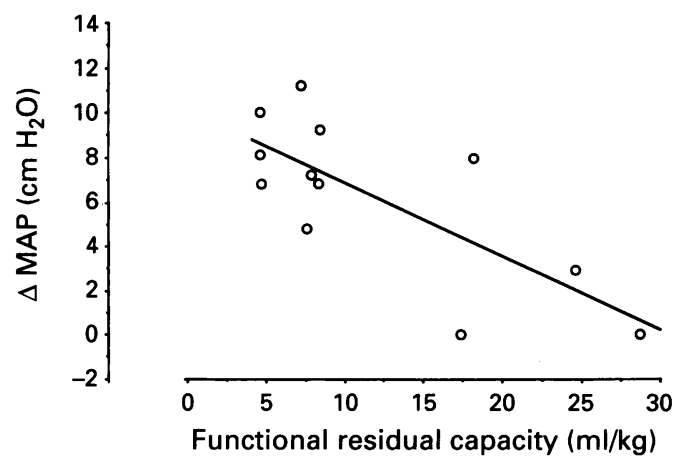

Figure 2 The correlation between the change $(\triangle)$ in $M A P$ to lung volume (FRC). Individual data and the regression line are shown. Regression equation: change in $M A P=-0.331 \mathrm{FRC}(\mathrm{ml} / \mathrm{kg})+10 \cdot 17(r=-0 \cdot 75)$.
MAP on conventional ventilation, compared with HFO, could achieve the same results, this would be more likely to increase complications as a result of barotrauma. An increase in MAP to improve oxygenation, however, is only relevant when the lung volume is low. In animals with healthy lungs, a change in the MAP level by modest amounts does not affect gas exchange, 89 whereas a large increase in MAP resulted in a deterioration in blood gases due to lung overdistension. ${ }^{10}$ Thus it is not surprising that in this series the two infants with MAS who had relatively high lung volumes did not improve on HFO when MAP was increased.

Infants were left at each MAP setting only for 10 minutes. We did not expect the maximum change in oxygenation after such a short period of time but it was our clinical experience $^{11}$ that if oxygenation would improve in response to an increase in MAP, a change, as documented by continuous monitoring, would have at least started to occur by 10 minutes. By allowing only 10 minutes at each MAP change, this facilitated the arrival of the infant at the optimal MAP level in the shortest time period. At the optimal level we then deliberately checked the arterial blood gas level after only 30 minutes, as we had already found such a time period sufficient for the maximum change in $\mathrm{PaO}_{2}$ to be experienced. ${ }^{1}$

Nine of the 12 infants were studied after surfactant administration. Exogenous surfactant replacement used during conventional ventilation affects oxygenation. The timing of the effect, however, is variable. ${ }^{12}$ Cotton et al noted a significant change only two hours after an artificial surfactant, but after 30 minutes with a natural surfactant. ${ }^{12}$ We therefore do not feel that the changes in oxygenation our infants experienced can be explained by the surfactant administration. Firstly, four were studied 60 minutes after receiving an artificial surfactant and thus would not be expected ${ }^{12}$ at that time to be experiencing an improvement in oxygenation. Secondly, a fifth infant, who had MAS and received surfactant, had no change in oxygenation on transfer to HFO. Thirdly, changes in oxygenation in response to MAP increases also occurred in infants not treated with surfactant. Lastly, the changes in $\mathrm{PaO}_{2}$ occurred within 10 minutes of a change in the MAP level and this response was seen repeatedly in most infants. We thus feel the improvements in oxygenation were as a consequence of the transfer to $\mathrm{HFO}$ and the high volume strategy pursued.

To measure FRC a low volume infant circuit was used. In most of the infants the two separate measurements yielded similar data (fig 1). Indeed there was only one infant in whom there was major discrepancy between the two results. Exclusion of that one outlier gave a coefficient of repeatability as low as $3.5 \mathrm{ml} / \mathrm{kg}$. The coefficient of repeatability in the ventilated infants was lower than that experienced in non-ventilated infants using either the same helium circuit or a nitrogen washout technique. ${ }^{4}$ All the infants were ventilated with shouldered endotracheal tubes. 
Previous measurements of tidal volume using such tubes have shown little evidence of leak, with minimal or no differences between the inspiratory and expiratory volumes. ${ }^{13}$ The values of FRC were within the ranges reported before. ${ }^{14-17}$

We had found before that it was not possible to identify before HFO those infants who would benefit from that mode of respiratory support by either their MAP level or $\mathrm{A}-\mathrm{aDO}{ }_{2} \cdot{ }^{11}$ In the present study, however, oxygenation did not improve in two of the four infants with the highest FRCs. The change in MAP needed to optimise oxygenation significantly correlated with the FRC on conventional ventilation. These data suggest that measurement of lung volume is useful to optimise oscillatory settings.

We deliberately chose to study a relatively diverse population who would be expected to have a range of lung volumes. This was for two reasons. Firstly, HFO has been shown in the clinical setting to benefit certain infants with all the diagnoses we studied and thus it was important to ensure our findings applied to these groups of patients. Secondly, the wide range of lung volumes in our patients ensures more thorough testing of the hypothesis. ${ }^{2}$ The finding that infants with the lowest lung volume required the greatest increase in MAP to optimise oxygenation would suggest that improvements in oxygenation experienced on transfer to HFO when a high volume strategy is used are due to the opening up of atelectatic lungs. Our sample size, however, was small and only a proportion of the patients received surfactant. We now plan, therefore, to study a larger cohort of infants to explore further the effect of diagnosis on the response to high volume strategy HFO.
Dr G Dimitriou is supported by the National Health System of Greece.

1 Chan V, Greenough A. Determinants of oxygenation during high frequency oscillation. Eur $\mathcal{F}$ Pediatr 1993; 152: 350-3.
Bryan AC. Reflections on the HIFI trial. Pediatrics 1991; 87: 565-7.

3 Fox WW, Schwartz JG, Shaffer TH. Effects of endotracheal tube leaks on functional residual capacity determination in intubated neonates. Pediatr Res 1979; 13: 60-4.

4 Yuksel B, Greenough A, Chan V, Ross Russel RI. Comparison of helium dilution and nitrogen washou measurements of functional residual capacity in premature infants. Pediatr Pulmonol 1993; 16: 197-200.

5 Hey EN. The relation between environmental temperature and oxygen consumption in the newborn baby. $\mathcal{F}$ Physiol 1969; 200: 589-603.

6 Bland M, Altman D. Statistical methods for assessing agreement between two methods of clinical measurement. ment between two meth

7 Chan V, Greenough A, Giffin F. Disease severity and optimum mean airway pressure level on transfer to high frequency oscillation. Pediatr Pulmonol 1994; 17: 178-82.

8 Courtney SD, Weber KR, Spohn WA, Malin SW, Bende $\mathrm{CV}$, Gotshall RW. Measurement of tidal volume using a pneumotachometer during high frequency oscillation. Crit Care Med 1990; 18: 651-3.

9 Kamitsuka MD, Boynton BR, Villanueva D, Vreeland PN, Frantz ID. Frequency, tidal volume and mean airway pressure combinations that provide adequate gas exchange and low alveolar pressure during high frequency oscillatory ventilation in rabbits. Pediatr Res 1990; 27: 64-9.

10 Schindler M, Seear M. The effect of lung mechanics on gas transport during high frequency oscillation. Pediatr transport during high fred

11 Chan V, Greenough A, Gamsu HR. High frequency oscillation for preterm infants with severe respiratory failure. Arch Dis Child 1994; 70: F44-6.

12 Cotton RB, Olsson T, Law AB, Parker RA, Lindström DP, Silberberg AR, et al. The physiological effects of surfactant treatment on gas exchange in newborn premature infants with hyaline membrane disease. Pediatr Res 1993 34: 495-501. 13 Hird M, Greenough A, Gamsu HR. Gas trapping during tional ventilators. Early Hum Dev 1990; 22: 51-6.

14 Bose C, Wood B, Bose G, Donlon D, Friedman M. Pulmonary function following positive pressure ventilation initiated immediately after birth in infants with respiratory distress syndrome. Pediatr Pulmonol 1990; 9: 244-50.

15 Edberg KE, Sandberg K, Silberberg A, Ekstrom J, Jodal B Hjalmarson $O$. Lung volume, gas mixing and mechanics of breathing in mechanically ventilated very low birthof breathing in mechanically ventilated very low birth-
weight infants with idiopathic respiratory distress synweight infants with idiopathic respirat

16 Richardson P, Bose CL, Carlstrom JR. The functional residual capacity of infants with respiratory distress. Acta Paediatrica Scandinavica 1986; 75: 267-71.

17 Sivan Y, Deakers TW, Newth CJL. Functional residua capacity in ventilated infants and children. Pediatr Re 1990; 28: 451-4. 